\title{
OPEN Artificial insemination and parthenogenesis in the whitespotted bamboo shark Chiloscyllium plagiosum
}

\author{
Jennifer T. Wyffels $1,7 \bowtie$, Lance M. Adams ${ }^{2}$, Frank Bulman ${ }^{3}$, Ari Fustukjian ${ }^{4,8}$,
} Michael W. Hyatt ${ }^{5,9}$, Kevin A. Feldheim ${ }^{6}$ \& Linda M. Penfold ${ }^{1}$

Non-lethal methods for semen collection from elasmobranchs to better understand species reproduction has accompanied the development of artificial insemination. Ejaculates $(n=82)$ collected from whitespotted bamboo sharks Chiloscyllium plagiosum $(n=19)$ were assessed and cold-stored raw or extended at $4^{\circ} \mathrm{C}$. Females $(n=20)$ were inseminated with fresh or $24-48 \mathrm{~h}$ cold-stored raw or extended semen and paternity of offspring determined with microsatellite markers. Insemination of females with fresh semen $(n=10)$ resulted in 80 hatchlings and $27.6 \%$ fertility. Insemination of females with semen cold-stored $24 \mathrm{~h}(\mathrm{n}=4)$ and $48 \mathrm{~h}(\mathrm{n}=1)$ semen resulted in 17 hatchlings and fertilization rates of $28.1 \%$ and $7.1 \%$ respectively. Two females inseminated with fresh or cold-stored semen laid eggs that hatched from fertilization and parthenogenesis within the same clutch. Parthenogenesis rate for inseminated females was $\mathbf{0 . 7 1 \%}$. Results demonstrate artificial insemination with cold-stored semen can provide a strategy for transport of male genetics nationally and internationally, precluding the need to transport sharks. Production of parthenotes in the same clutch as sexually fertilized eggs highlights the prevalence of parthenogenesis in whitespotted bamboo sharks and poses important considerations for population management.

Whitespotted bamboo sharks Chiloscyllium plagiosum are endemic to the Indo-West Pacific Ocean and common in aquariums worldwide because of their longevity, successful reproduction under managed care and small size. They are classified as "Near Threatened" by the International Union for Conservation of Nature (IUCN) Red List $^{1,2}$ due to habitat destruction and unmanaged fisheries activity. Whitespotted bamboo sharks are oviparous and reproduce readily in aquaria laying eggs in pairs, every 6-7 days during a 2-3 month annual laying cycle ${ }^{3-6}$.

Whitespotted bamboo females do not require frequent and repeated mating during their laying season and instead use sperm stored in the nidamental (shell or oviducal) gland to fertilize eggs ${ }^{3,4}$. Whitespotted bamboo sharks also have been shown to reproduce parthenogenetically, adding another level of complexity to managing reproduction ${ }^{7,8}$. To facilitate reproduction and maintain genetic diversity, assisted reproductive technologies including artificial insemination (AI) are one solution ${ }^{9,10}$ that avoids the extra challenges, risks and costs associated with transporting sharks between institutions. Artificial insemination among elasmobranchs with the production of offspring has been accomplished for four shark species, including this species, (cloudy catshark Scyliorhinus torazame ${ }^{11}$, whitespotted bamboo shark C. plagiosum ${ }^{12}$, brownbanded bamboo shark Chiloscyllium punctatum $^{9}$, zebra or leopard shark Stegostoma tigrinum $^{9}$ ) and one skate species, (clearnose skate Rostroraja eglanteria ${ }^{13}$ ) using freshly collected, but not cold-stored semen.

The first steps for developing AI for many species include semen collection and characterization. Semen for analysis has historically been collected from elasmobranchs following euthanasia ${ }^{14-21}$ but more recently, protocols for non-lethal sampling have been developed ${ }^{22}$. Cold storage $\left(1-4^{\circ} \mathrm{C}\right)$ is an easy and convenient method for

${ }^{1}$ South-East Zoo Alliance for Reproduction \& Conservation, Yulee, FL 32097, USA. ${ }^{2}$ Aquarium of the Pacific, 100 Aquarium Way, Long Beach, CA 90802, USA. ${ }^{3}$ Ripley's Aquarium of the Smokies, 88 River Road, Gatlinburg, TN 37738, USA. ${ }^{4}$ The Florida Aquarium, 701 Channelside Drive, Tampa, FL 33602, USA. ${ }^{5}$ Adventure Aquarium, 1 Riverside Drive, Camden, NJ 08103, USA. ${ }^{6}$ Pritzker Laboratory for Molecular Systematics and Evolution, Field Museum of Natural History, 1400 S. Lake Shore Drive, Chicago, IL 60605, USA. ${ }^{7}$ Present address: University of Delaware, Center for Bioinformatics \& Computational Biology, 590 Avenue 1743, Newark, DE 19713, USA. ${ }^{8}$ Present address: Loveland Living Planet Aquarium, 12033 Lone Peak Pkwy, Draper, UT 84020, USA. ${ }^{9}$ Present address: New York Aquarium, Wildlife Conservation Society, 602 Surf Ave., Brooklyn, NY 11224, USA. ${ }^{\circledR}$ email: wyffels@udel.edu 


\begin{tabular}{|l|l|l|l|l|}
\hline & $\mathbf{n}^{*}$ & mean \pm SE & median & range \\
\hline Volume (ml) & $19(82)$ & $0.61 \pm 0.08$ & 0.52 & $0.05-2.3$ \\
\hline Sperm concentration $\left(10^{6} / \mathrm{ml}\right)$ & $19(73)$ & $858 \pm 129$ & 799.5 & $3-4670$ \\
\hline Spermatazeugmata (\%) & $19(76)$ & $23.51 \pm 5.74$ & 20 & $0-25$ \\
\hline Plasma membrane integrity (\%) & $18(80)$ & $64 \pm 5$ & 71.05 & $49-95$ \\
\hline Total motility (\%) & $16(61)$ & $65 \pm 6$ & 74.6 & $39-95$ \\
\hline Progressive motility (\%) & $19(79)$ & $19 \pm 4$ & 17.5 & $1-70$ \\
\hline pH & $19(78)$ & $6.28 \pm 0.04$ & 6.28 & $5.5-7.5$ \\
\hline Osmolarity (mOsm) & $16(60)$ & $1091 \pm 34$ & 1115.86 & $682-1410$ \\
\hline
\end{tabular}

Table 1. Whitespotted bamboo shark Chiloscyllium plagiosum semen characteristics. ${ }^{\star}$ Sharks (ejaculates).

short-term preservation of fish sperm and eggs for hours to weeks with the conditions of storage such as antibiotics and diluents optimized for each species ${ }^{23-28}$. Gamete cold storage does not require specialized equipment and could be useful in aquariums to allow the movement of genetic material between institutions to maintain gene diversity in a population without the need to transport an animal. This is especially useful as cryopreservation research using elasmobranch semen is limited to a few species of stingray ${ }^{9,15}$ and investigation into cryopreservation of semen from whitespotted bamboo sharks has not yielded viable sperm (Wyffels, unpublished).

The ability of elasmobranchs to reproduce by parthenogenesis is widely known for sharks (swell shark Cephaloscyllium ventriosum ${ }^{29}$; bonnethead shark Sphyrna tiburo ${ }^{30}$; blacktip shark Carcharinus limbatus ${ }^{31}$; whitespotted bamboo C. plagiosum ${ }^{7}$ and zebra sharks S. tigrinum $^{32,33}$ ) and rays (spotted eagle ray Aetobatus narinari ${ }^{34}$ ), and documented for wild smalltooth sawfish Prisitis pectinata ${ }^{35}$. The strategy behind this form of reproduction is unknown, but it may be a reproductive adaptation for females after prolonged periods without male interaction. As such, it is assumed to occur instead of fertilization from a male. From a population management perspective, parthenotes do not contribute to the genetic diversity of a population and are rather female 'clones' of the dam. The overall incidence of parthenogenesis in whitespotted bamboo sharks is currently unknown, but realizing the incidence of parthenogenesis would aid with population modeling. Microsatellite markers have been developed previously to examine parentage in the whitespotted bamboo shark ${ }^{7,43}$.

The objectives of this study were to: (1) develop a safe and reliable method for non-lethal collection and characterization of semen from whitespotted bamboo sharks; (2) examine the effects of cold storage on sperm longevity; (3) produce offspring following AI with fresh and cold-stored semen; (4) develop additional microsatellite markers to confirm parentage of AI offspring; and (5) determine the incidence of parthenogenesis in whitespotted bamboo sharks.

\section{Results}

Ejaculate characteristics. Ejaculate collection was explored using two techniques (catheterization and manual expression) and collection by manual expression became the default collection method because of its relative simplicity and efficiency. A total of 82 ejaculates from 19 sharks were collected all months of the year attempted and semen characteristics are presented in Table 1. Ejaculates were light brown or buff colored, opaque and viscous containing individual sperm and spermatozeugmata composed of radially arrayed sperm with heads that were closely aligned and embedded in a matrix core (Fig. 1a) ${ }^{21}$. Spermatozeugmata were observed in $48 \%$ of ejaculates irrespective of time of year. Spermatozoa had elongated helical heads (Fig. 1c) with an apical acrosome that was stained by Arachis hypogaea lectin or peanut agglutinin (PNA) (Fig. 1b-e). Sperm morphology was $100 \%$ normal for all ejaculates. The length of the head, midpiece and flagellum as well as the number of gyres for spermatozoa are shown in Table 2.

Spermatozoa in raw ejaculates had little or no motility but acquired motility after dilution in artificial seawater (ASW). After dilution in ASW, the cytoplasmic sleeve, found at the junction of the midpiece and tail (Fig. 1c), was observed to slide toward the distal end of the flagellum until it was shed from the spermatozoa. Shed cytoplasmic sleeves accumulated at the peripheral margin of the spermatozeugmata. Individual, free spermatozoa moving progressively had serpentine tails and demonstrated rotation about the long axis.

Short-term semen storage. Sample preparation method $(p<0.05)$ and duration of cold storage $(p<0.05)$ affected plasma membrane integrity (PMI) and total motility with diluted samples and shorter storage times resulting in higher PMI and total motility (Fig. 2). There was a strong positive correlation between sperm PMI and total motility $(\mathrm{r}=0.93, \mathrm{n}=82, p<0.001)$. There were no observed differences in PMI or total motility for semen extended in either ASW or elasmobranch adjusted Hank's balanced salt solution (E-HBSS), both of which supported sperm motility and PMI for up to 18 days (Fig. 2). Semen stored raw retained PMI, however was completely immotile by day 18 . Cold storage of raw ejaculate for $24 \mathrm{~h}$ did not affect PMI $(p=0.268)$ but total motility decreased $(p=0.009)$. For semen cold-stored for 2-7 days, ejaculates extended in ASW or E-HBSS had higher PMI and motility than samples stored raw $(p<0.05$, Fig. 2$)$. Samples stored raw declined in quality the fastest of the three preparation methods and had the lowest PMI and total motility each day samples were evaluated (Fig. 2). 

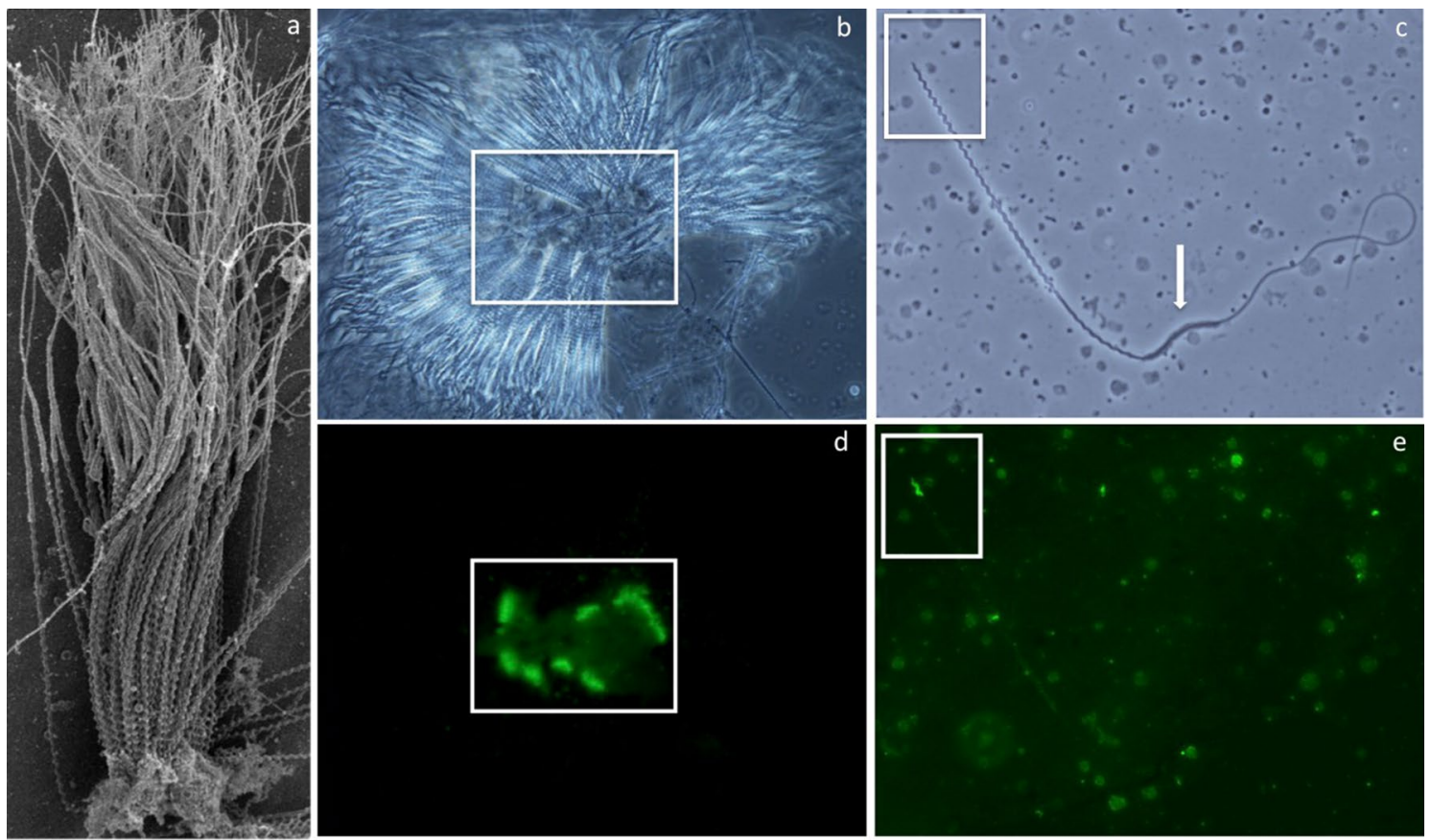

Figure 1. Whitespotted bamboo shark Chiloscyllium plagiosum spermatozuegmata and spermatozoa micrographs illustrating the morphology and acrosome location for aggregated and individual spermatozoa. Scanning electron micrograph of a spermatozeugma fragment (a) revealing sperm with heads closely aligned and embedded in a matrix core. Matching phase contrast and fluorescent micrographs of a spermatozeugma with radially aligned heads $(\mathbf{b}, \mathbf{d})$ and individual spermatozoan $(\mathbf{c}, \mathbf{e})$ with acrosomes highlighted by fluorescein isothiocyanate conjugated Arachis hypogaea agglutinin (PNA-FITC) stain. Whitespotted bamboo shark spermatozoa (c) possess a helical head with an acrosome (e), a helical midpiece and a flagellum with a transient cytoplasmic sleeve (arrow) at the junction of the midpiece and tail that was shed after acquiring motility.

\begin{tabular}{|l|l|}
\hline & Length $(\boldsymbol{\mu}$ m) mean \pm SE \\
\hline Total & $178.3 \pm 0.8$ \\
\hline Head & $57.7 \pm 0.2$ \\
\hline Midpiece & $19.9 \pm 0.2$ \\
\hline Flagellum & $100.7 \pm 0.6$ \\
\hline Acrosome & $3.0 \pm 0.1$ \\
\hline & Gyres \\
\hline Total (Head \& Midpiece) & $34.8 \pm 0.1$ \\
\hline Head & $25.9 \pm 0.1$ \\
\hline
\end{tabular}

Table 2. Whitespotted bamboo shark Chiloscyllium plagiosum spermatozoa morphometrics. Lengths from digital image analysis of 10 spermatozoa per shark from five sharks were measured and summarized as a mean and standard error (SE).

Artificial insemination and paternity. The time for insemination of each female took approximately $10 \mathrm{~min}$ and no adverse effects were observed. If egg cases were present in the oviduct the procedure was more challenging but the egg cases are leathery and durable and none were physically affected by the AI procedure, as evidenced by all egg cases laid being without damage. No eggs laid during the six weeks prior to AI developed. Fifteen females laid 114 fertile eggs resulting in 97 hatchlings after insemination and there was considerable variation in the number of eggs laid (1-43), duration or number of days of fertility (1-107), fertility (4.2-66.7\%) and hatchability (2.6-60.0\%) between females receiving $100-750 \times 10^{6}$ spermatozoa in raw and extended inseminates.

Five females laid eggs $(n=66) 1-153$ days after AI but none were fertile (Table 3). For most females $(n=9)$, all fertile eggs completed development successfully, but three females laid one fertile egg, two females laid two fertile eggs, and one female laid seven fertile eggs that all died before hatching (Supplemental Table 1). Average ( \pm standard deviation) incubation was $117 \pm 10$ days and ranged from $74-142$ days $(n=73)$. Successful insemination of both oviducts was confirmed by observation of development of eggs laid as pairs and was observed for five females that incidentally also had the highest fertility (37.5-66.7\%) and hatchability (34.4-60.0\%) rates (Table 3). Bilateral insemination success was not associated with inseminate age (fresh or $24 \mathrm{~h}$ ), preparation 
a

100

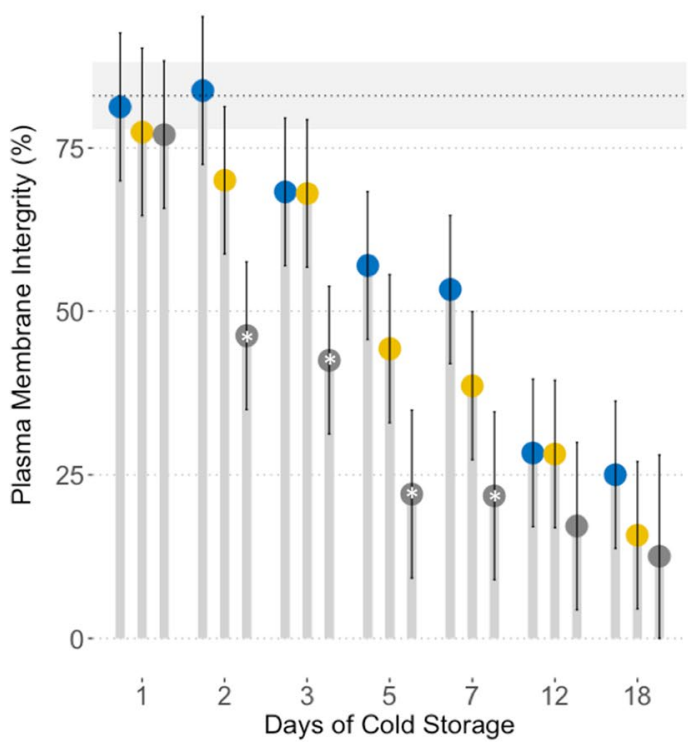

b

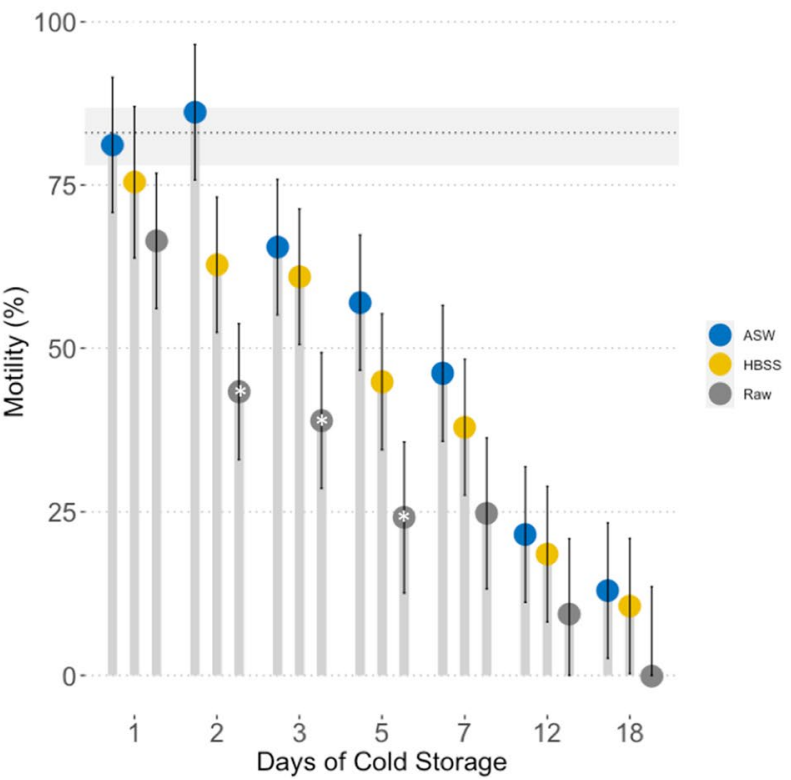

Figure 2. The effect of cold storage on whitespotted bamboo shark Chiloscyllium plagiosum ejaculates. Plasma membrane integrity (a) and motility (b) of ejaculates cold-stored raw or extended with elasmobranch modified Hank's balanced salt solution (E-HBSS) or artificial seawater (ASW) and initial mean (dotted line) and standard error (grey rectangle) of ejaculates. Treatment bars are capped with a circle (estimated marginal mean) and error bars (95\% confidence interval). ${ }^{\star}$ Indicates significant difference among treatments at each time point $(p<0.05)$.

\begin{tabular}{|c|c|c|c|c|c|c|c|c|}
\hline \multirow{2}{*}{$\begin{array}{l}\text { Female } \\
\text { ID }\end{array}$} & \multirow{2}{*}{$\begin{array}{l}\text { Male ID-ejaculate } \\
\text { ID }\end{array}$} & \multirow{2}{*}{$\begin{array}{l}\text { Egg cases } \\
\text { laid }\end{array}$} & \multirow{2}{*}{$\begin{array}{l}\text { Fertility duration } \\
\text { (days) }\end{array}$} & \multirow[b]{2}{*}{ Days fertile } & \multicolumn{2}{|c|}{ Hatchlings } & \multirow[b]{2}{*}{ Fertility (\%) } & \multirow[b]{2}{*}{ Hatchability (\%) } \\
\hline & & & & & AI & $\mathbf{P}$ & & \\
\hline 854 & 320-E1 & 43 & 107 & $14-121$ & 9 & 1 & $26.8 \%$ & $22.0 \%$ \\
\hline 101 & 381-E2 & 30 & 103 & $8-111$ & 15 & - & $56.7 \%$ & $50.0 \%$ \\
\hline 283 & 381-E4 & 32 & 101 & $15-116$ & 18 & 0 & $66.7 \%$ & $60.0 \%$ \\
\hline 268 & 381-E5 & 36 & 97 & $6-103$ & 14 & 0 & $58.3 \%$ & $38.9 \%$ \\
\hline 793 & 395-E1^^ & 27 & 69 & $10-79$ & 12 & 0 & $52.2 \%$ & $52.2 \%$ \\
\hline 036 & 320-E3 & 34 & 51 & $12-63$ & 11 & 0 & $37.5 \%$ & $34.4 \%$ \\
\hline 581 & 381-E1 & 32 & 55 & $8-63$ & 3 & 0 & $12.9 \%$ & $9.7 \%$ \\
\hline 512 & 381-E3 & 12 & 49 & $11-60$ & 3 & 0 & $27.3 \%$ & $27.3 \%$ \\
\hline 034 & 381-E3 & 19 & 44 & $16-60$ & 5 & 0 & $26.3 \%$ & $26.3 \%$ \\
\hline 370 & 2969-E1* & 18 & 30 & $19-49$ & 2 & 0 & $11.1 \%$ & $11.1 \%$ \\
\hline 785 & 381-E4 & 26 & 1 & 10 & 1 & 0 & $4.2 \%$ & $4.2 \%$ \\
\hline 376 & 381-E1 & 14 & 1 & 44 & 1 & 0 & $7.1 \%$ & $7.1 \%$ \\
\hline 307 & 320-E1 & 39 & 1 & 13 & 1 & 2 & $7.7 \%$ & $2.6 \%$ \\
\hline 626 & 395-E1^ & 19 & 1 & 59 & 1 & 0 & $20.0 \%$ & $20.0 \%$ \\
\hline 583 & 395-E1^ & 22 & 1 & 60 & 1 & 0 & $9.1 \%$ & $9.1 \%$ \\
\hline 063 & 381-E2 & 16 & 0 & - & 0 & 0 & $0 \%$ & $0 \%$ \\
\hline 775 & 381-E3 & 16 & 0 & - & 0 & 0 & $0 \%$ & $0 \%$ \\
\hline 551 & 381-E5 & 6 & 0 & - & 0 & 0 & $0 \%$ & $0 \%$ \\
\hline 065 & 320-E2 & 26 & 0 & - & 0 & 0 & $0 \%$ & $0 \%$ \\
\hline 095 & 320-E2 & 2 & 0 & - & 0 & 0 & $0 \%$ & $0 \%$ \\
\hline
\end{tabular}

Table 3. Outcome of whitespotted bamboo sharks Chiloscyllium plagiosum artificial insemination trials. Hatchlings: developed from sexual fertilization (AI) or parthenogenetically (P) after artificial insemination. ${ }^{\star}$ Indicates semen shipped overnight from Adventure Aquarium, NJ, to Aquarium of the Pacific, CA, for artificial insemination. ^ Indicates semen shipped overnight from The Florida Aquarium, FL, to Ripley's Aquarium of the Smokies, TN, for artificial insemination. Bold fertility and hatchability percentages indicate females where artificial insemination was confirmed bilaterally successful. 


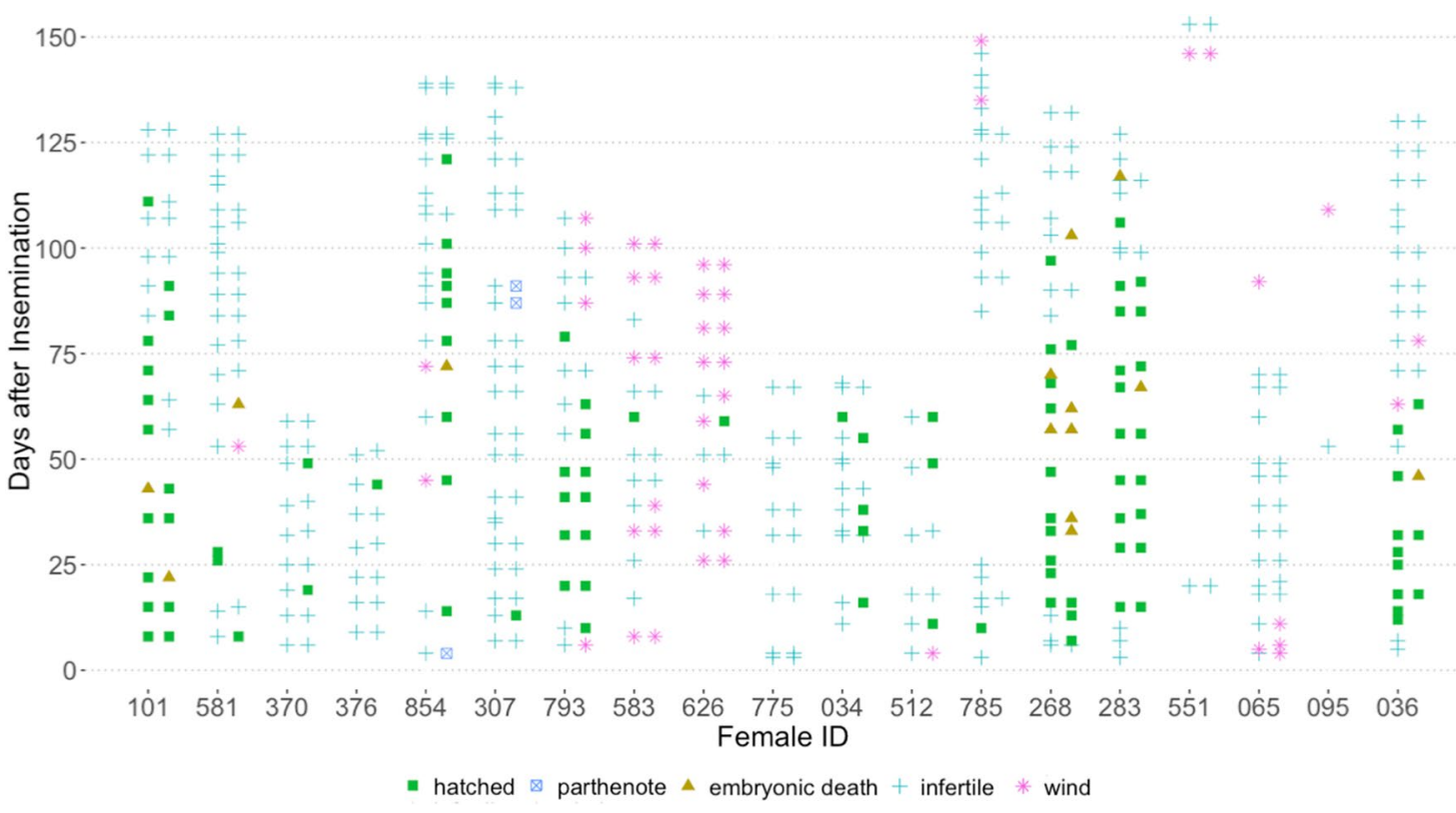

Figure 3. Oviposition dates for whitespotted bamboo shark Chiloscyllium plagiosum females after artificial insemination. Egg cases are usually laid in pairs, one egg from each side of the paired reproductive tract. Egg cases classified as fertile were assigned to categories: hatched, parthenote or embryonic death. Egg cases classified as infertile had ova without evidence of embryonic development. Empty or wind egg cases did not contain ova.

(raw or extended), or sperm dose $\left(100-750 \times 10^{6}\right.$ total sperm) and therefore possibly related to the technique. For the remainder of the females in successful trials $(n=10)$, only one of a pair of egg cases laid together was fertile (Fig. 3).

The combined average number of egg cases laid per females in successful trials was 24, double the combined average number of egg cases laid by females in unsuccessful trials, 12 . The average fertility duration for females that produced nine or more hatchlings $(n=6)$ was $88 \pm 9$ days compared to $45 \pm 5$ days for females that produced $2-5$ hatchlings $(n=4)$ (Table 3). All eggs laid for 43 days after AI were fertile for female (ID 101) and one egg hatched from the first pair of egg cases laid after AI by four females on day six, eight or 13 post-insemination (Fig. 3). Remaining females $(n=11)$ laid 1-10 infertile eggs before their first fertilized egg. Although females continued to lay fertile eggs for up to 121 days after insemination, fertility peaked by four weeks and decreased incrementally after 10 weeks (Fig. 4). All females that laid one or more fertile eggs also laid multiple infertile eggs afterwards, at the end of their laying cycle. Two females laid a single fertile egg 10 or 13 days post-insemination but not afterwards. Time from AI to laying date for the first fertilized egg ranged from 6-60 days and females laid fertile eggs 6-121 days after AI for 1-107 days (Table 3). There was no difference in fertility for ejaculates that were split and inseminated as raw semen or semen extended 1:1 with ASW (paired t-test: $\mathrm{t}=-0.08, \mathrm{df}=3$, $p=0.9424$ ). Collectively, nine females laid 61 fertilized eggs after AI using raw semen compared to 50 fertilized eggs laid by six females inseminated with extended semen (Supplemental Table 1).

Inseminates varied in sperm number from 3-750 $\times 10^{6}$ spermatozoa and fertile eggs resulted from all doses except the lowest dose, $3 \times 10^{6}$ spermatozoa. However, only one of the two females that received the lowest dose laid eggs regularly post-insemination and can be considered in analyses. Insemination using 100-750 $\times 10^{6}$ spermatozoa was effective and there was high variability in the number of hatchlings produced among the females even when using semen from the same male. For example, among 10 females inseminated with fresh semen from male 381, seven females produced 1-18 hatchlings each and three females produced no hatchlings (Supplemental Table 1).

Cold-stored semen successfully fertilized eggs for up to $48 \mathrm{~h}$ after collection and inseminates from $24 \mathrm{~h}$ coldstored semen had similar fertility and hatchability as inseminates from fresh semen. The same ejaculate split and used fresh and after $48 \mathrm{~h}$ of cold storage both fertilized eggs with three hatchlings from the fresh inseminate and one from the cold-stored inseminate. Two males contributed semen that was cold-stored for $24 \mathrm{~h}$ and shipped overnight between aquaria before being used for insemination, and both ejaculates fertilized eggs. Semen collected from male 395 at The Florida Aquarium and shipped overnight for AI trials at Ripley's Aquarium of the Smokies was used to inseminate three females that resulted in a total of 14 hatchlings. Semen from Adventure Aquarium male 2969 was shipped to Aquarium of the Pacific and used to inseminate a female that laid two fertile eggs that successfully hatched. Combined, 17 hatchlings resulted from AI of five females with cold-stored semen from three males from three aquaria.

Parthenogenesis. To determine the general incidence of parthenogenesis, 1053 eggs collected over 105 days from a habitat with 48 females were incubated and monitored for embryo development. Five eggs from 


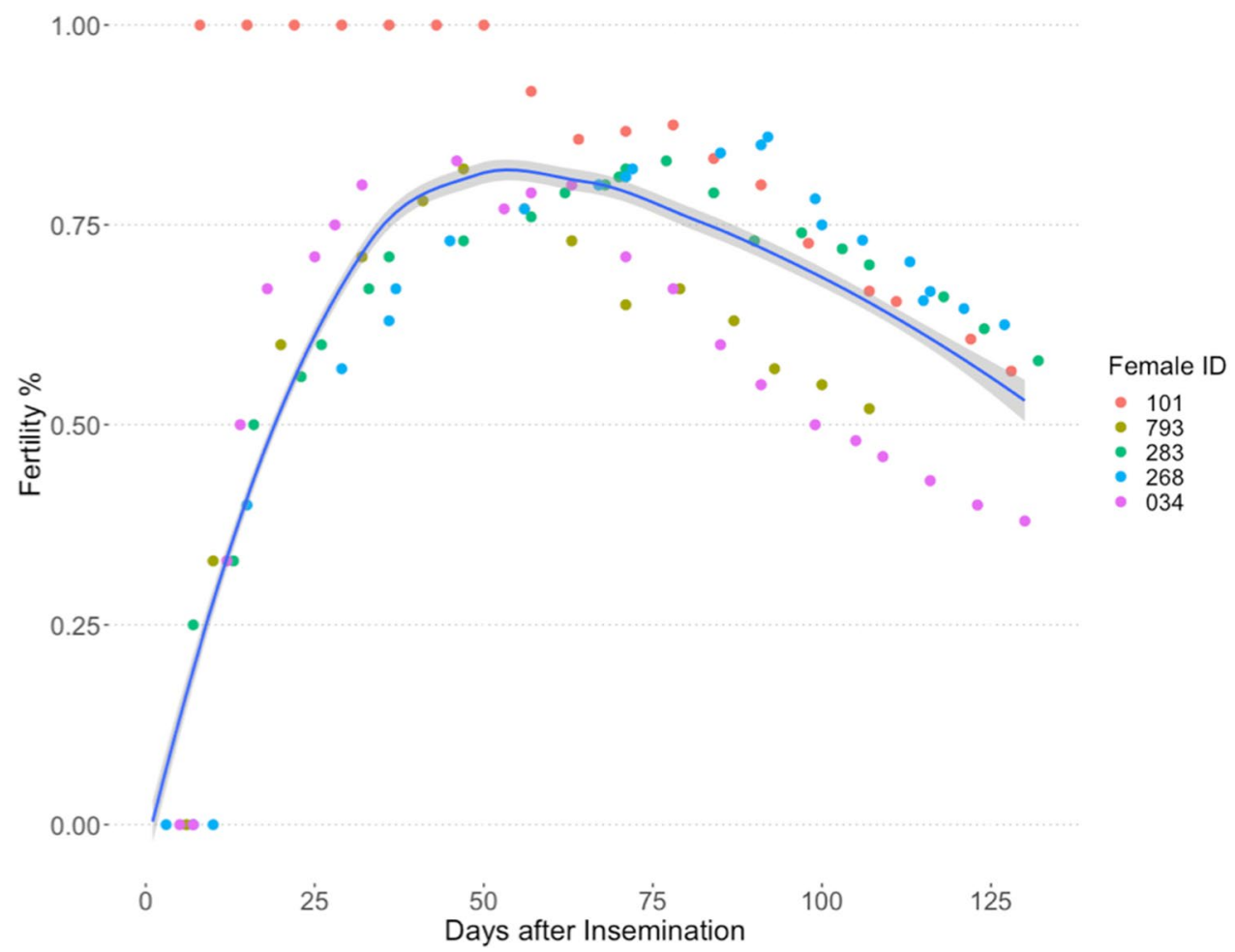

Figure 4. Fertility, expressed as a percentage of egg cases laid, for five females that stored sperm for more than 3 months from artificial insemination and laid pairs of fertile eggs. Fertility (smoothed loess local regression line) with 95\% confidence interval (grey) for females $(n=5)$ beginning 6 days after and ending 116 days after artificial insemination. Individual female fertility is distinguished by marker color.

28 fertile eggs hatched. The hatchlings and nine of the 23 embryos (no DNA samples could be collected from 14) were genotyped and all hatchlings and seven of the nine embryos were parthenotes, which accounts for $1.1 \%$ of eggs laid. If the remaining embryos that could not be genotyped $(n=14)$ were all parthenotes, the maximum incidence of parthenogenesis in this population would be $2.5 \%$. The minimum number of females responsible for parthenotes was four accounting for $8.3 \%$ of the 48 females, however some females in the population may not have been laying eggs, making the incidence higher (Table 4).

Two of 20 inseminated females laid eggs with embryos that developed via automictic parthenogenesis, confirmed by homozygosity at all microsatellite loci. The first female that reproduced via parthenogenesis (ID 854) laid a pair of eggs four days after AI, one was infertile and the other was a parthenote. The earliest fertile eggs from AI including all females were laid 6 days after AI. Following the production of this parthenote, an additional 14 eggs were laid and seven hatched and were confirmed to be the result of AI (Fig. 4). There were 10 days between laying of the parthenote and the next AI fertilized egg. The second female that reproduced via parthenogenesis (ID 307) laid 28 eggs but only three hatched. The first egg that hatched was one of a pair of eggs laid 13 days after insemination, preceded by a pair of infertile eggs laid seven days after fertilization. This hatchling was confirmed fertilized from AI. An additional 20 infertile eggs were laid during the next 74 days followed by the last eggs laid on days 87 and 91 after AI. One egg of each of the final two pairs was infertile but the other developed via automictic parthenogenesis and hatched. There were 80 and 83 days between the AI fertilized egg and each parthenote respectively. The incidence of parthenogenesis (parthenote/total number of eggs) was $0.71 \%$ among this group of females, compared to $1.1 \%$ described above.

\section{Discussion}

This study demonstrates that offspring can be produced from AI of whitespotted bamboo sharks with sperm coldstored for up to $48 \mathrm{~h}$. Following a single insemination, fertilized eggs were obtained for a period of 1-107 days up to 121 days after AI, confirming sperm storage for this species. Proof of paternity for whitespotted bamboo shark hatchlings was confirmed using existing and newly developed microsatellite loci, but also identified parthenotes within the same clutch of fertilized eggs for two females.

Whitespotted bamboo shark semen was able to be collected throughout the year. In the wild, these sharks reproduce seasonally with documented seasonal changes in the gonadosomatic and hepatosomatic index for both male and females ${ }^{3}$. However, semen collection was not attempted in these studies, so it is possible that while the gonadosomatic index of males changed seasonally, semen may have been present year-round. Additionally, there may be changes in semen quality that accompany a seasonal reproductive pattern, as has been described for seasonal terrestrial species ${ }^{36}$ but which were not examined in this study. 


\begin{tabular}{|c|c|c|c|c|c|c|c|c|c|c|}
\hline Female ID & Egg ID ${ }^{*}$ & Cp1 & Cpl 80 & Cpl 150 & Cpl 471 & Cpl 930 & Cpl 1163 & Cpl 962 & Cpl 1161 & Cpl 1141 \\
\hline \multicolumn{2}{|l|}{ Female 1} & $289 / 315$ & $266 / 282$ & $200 / 202$ & $226 / 228$ & $178 / 182$ & $201 /$ & $356 /$ & $194 / 210$ & $186 / 194$ \\
\hline & P1 & $315 / 315$ & $266 / 266$ & 202/202 & \begin{tabular}{|l|}
$226 / 226$ \\
\end{tabular} & $182 / 182$ & $201 / 201$ & $356 / 356$ & 194/194 & 194/194 \\
\hline & P2 & $289 / 289$ & $282 / 282$ & $200 / 200$ & \begin{tabular}{|l|}
$226 / 226$ \\
\end{tabular} & $178 / 178$ & $201 / 201$ & $356 / 356$ & $210 / 210$ & $186 / 186$ \\
\hline & P3 & $289 / 289$ & $266 / 266$ & 202/202 & $\mid 228 / 228$ & $182 / 182$ & $201 / 201$ & $356 / 356$ & \begin{tabular}{|l|}
$194 / 194$ \\
\end{tabular} & \begin{tabular}{|l|}
$194 / 194$ \\
\end{tabular} \\
\hline & P4 & $315 / 315$ & $266 / 266$ & $202 / 202$ & $226 / 226$ & $178 / 178$ & $201 / 201$ & \begin{tabular}{|l|}
$356 / 356$ \\
\end{tabular} & $210 / 210$ & $194 / 194$ \\
\hline \multicolumn{2}{|l|}{ Female 2} & $289 /$ & $274 / 294$ & $194 / 202$ & $228 /$ & $176 / 182$ & $193 /$ & $368 /$ & $200 / 210$ & 194/ \\
\hline & P5 & $289 / 289$ & $294 / 294$ & 194/194 & \begin{tabular}{|l|}
$228 / 228$ \\
\end{tabular} & $182 / 182$ & $193 / 193$ & $368 / 368$ & $210 / 210$ & \begin{tabular}{|l|}
$194 / 194$ \\
\end{tabular} \\
\hline & P6 & $289 / 289$ & $274 / 274$ & $202 / 202$ & $228 / 228$ & $176 / 176$ & $193 / 193$ & $368 / 368$ & $210 / 210$ & $194 / 194$ \\
\hline & P7 & $289 / 289$ & $294 / 294$ & 202/202 & \begin{tabular}{|l}
$228 / 228$ \\
\end{tabular} & $182 / 182$ & $193 / 193$ & $368 / 368$ & $200 / 200$ & 194/194 \\
\hline & P8 & $-1-$ & $294 / 294$ & $-1-$ & $-1-$ & $-1-$ & $193 / 193$ & $356 / 356$ & $200 / 200$ & 194/194 \\
\hline \multicolumn{2}{|l|}{ Female 3} & $289 / 289$ & $266 / 282$ & $194 /-$ & $228 /-$ & $176 / 182$ & $201 /-$ & $364 /-$ & $198 / 210$ & $186 / 194$ \\
\hline & P9 & $289 / 289$ & $282 / 282$ & 194/194 & $228 / 228$ & $182 / 182$ & $201 / 201$ & $-1-$ & $210 / 210$ & $186 / 186$ \\
\hline & P10 & $289 / 289$ & $266 / 266$ & 194/194 & \begin{tabular}{|l|}
$228 / 228$ \\
\end{tabular} & $176 / 176$ & $201 / 201$ & $364 / 364$ & $198 / 198$ & $194 / 194$ \\
\hline & P11 & $289 / 289$ & $266 / 266$ & 194/194 & \begin{tabular}{|l|}
$228 / 228$ \\
\end{tabular} & $182 / 182$ & $201 / 201$ & $364 / 364$ & $210 / 210$ & $194 / 194$ \\
\hline \multicolumn{2}{|l|}{ Female 4} & $315 /-$ & $266 /-$ & 194/- & $226 /-$ & $178 /-$ & $193 /-$ & $368 /-$ & $200 /-$ & $194 /-$ \\
\hline & P12 & $315 / 315$ & $266 / 266$ & 194/194 & \begin{tabular}{|l|}
$226 / 226$ \\
\end{tabular} & $178 / 178$ & $193 / 193$ & \begin{tabular}{|l|}
$368 / 368$ \\
\end{tabular} & $200 / 200$ & 194/194 \\
\hline \multicolumn{2}{|l|}{ Female 854} & $315 / 315$ & $266 / 286$ & 194/194 & \begin{tabular}{|l|}
$226 / 228$ \\
\end{tabular} & $176 / 178$ & $193 / 193$ & $304 / 368$ & $198 / 200$ & $186 / 194$ \\
\hline & AI-P1 & $315 / 315$ & $286 / 286$ & 194/194 & $226 / 226$ & $176 / 176$ & $193 / 193$ & $304 / 304$ & $198 / 198$ & $186 / 186$ \\
\hline \multicolumn{2}{|l|}{ Female 307} & $315 / 315$ & $274 / 274$ & 194/194 & \begin{tabular}{|l|}
$226 / 228$ \\
\end{tabular} & $182 / 182$ & $193 / 201$ & $360 / 364$ & $200 / 208$ & $186 / 194$ \\
\hline & AI-P2 & $315 / 315$ & $274 / 274$ & 194/194 & \begin{tabular}{|l|}
$226 / 226$ \\
\end{tabular} & $182 / 182$ & $201 / 201$ & $360 / 360$ & $208 / 208$ & 194/194 \\
\hline & AI-P3 & $315 / 315$ & $274 / 274$ & 194/194 & $228 / 228$ & $182 / 182$ & $193 / 193$ & $364 / 364$ & $200 / 200$ & $186 / 186$ \\
\hline
\end{tabular}

Table 4. Whitespotted bamboo shark Chiloscyllium plagiosum female and parthenote microsatellite loci. ${ }^{\star} \mathrm{P} 1-$ P12 eggs were laid by females housed without males and not inseminated, AI-P eggs were laid by inseminated females; - Indicates failed loci; missing data represent loci that could not be determined by genotype reconstruction.

Whitespotted bamboo shark semen was confirmed to include spermatozeugmata, sperm aggregates with heads aligned and embedded in a binding matrix ${ }^{21}$. Spermatozeugmata are observed for many shark species ${ }^{21,37}$ and may serve to minimize sperm loss during copulation, increase efficiency of male and female sperm storage, or preserve longevity and motility of sperm during storage $e^{21}$. In this study a single insemination produced fertilized eggs for up to 121 days, demonstrating sperm storage for nearly 4 months. This duration of sperm storage and oviposition is similar to females newly collected from the wild in the months prior to the egg laying season and maintained in aquaria ${ }^{3}$ as well as females that have been maintained in aquaria for several years ${ }^{4,6,12}$, demonstrating the safety and efficacy of AI to facilitate reproduction of this species under managed care.

Progressively motile spermatozoa had persistent flagellar motion and rotated or rolled about their long axis as has been described for other sharks ${ }^{16,22}$ and rays ${ }^{19}$ as well as other vertebrates ${ }^{38}$ suggesting both motions are necessary for movement within the female reproductive tract and fertilization. Occasionally, individual progressively motile spermatozoa demonstrated periodic bursts of increased rapid forward progression especially when encountering cellular debris blocking their path forward. Spermatozoa heads were not flexible and therefore the increased forward speed may assist penetration of the protective layers surrounding the egg and be beneficial for fertilization. Spermatozoa also displayed reverse motility on occasion, similar to what has been described for other shark species ${ }^{16,22}$. Reverse motility is not a common spermatozoa characteristic and the role in sharks is not yet clear but could be a mechanism to liberate sperm from spermatozeugmata or be related to sperm binding sites during storage in the nidamental gland ${ }^{22}$. Further studies are needed to understand the significance and role of reverse motility for shark spermatozoa.

Removing the seminal plasma and resuspending in ASW resulted in greater sperm longevity of cold-stored sperm than cold storage of raw semen alone and sperm membrane integrity was maintained longer than sperm motility. These findings are in keeping with observations in the freshwater ocellate stingray Potamotrygon motoro, where extension of semen in saline or HBSS resulted in longer durations of motility than raw semen alone ${ }^{14}$. Loss of motility before PMI was observed, which was similarly observed in teleosts ${ }^{39,40}$. Insemination of females with raw semen cold-stored raw for $24 \mathrm{~h}$ or $48 \mathrm{~h}$ resulted in offspring production, but the low fertilization rate (7\%) using $48 \mathrm{~h}$ semen suggests that washing sperm free of seminal plasma prior to shipping may confer some benefit to sperm survival prior to AI and should be investigated in the future.

The role of the male siphon sac in insemination supposed from mating observations is to aid in transfer of semen to the female through the clasper, presumably admixing the ejaculate with seawater, which would induce motility in the sperm. To attempt to investigate this role, ejaculates were either inseminated raw or extended 1:1 in ASW to mimic the mating process and induce sperm motility. Both inseminate preparation techniques produced a similar number of fertile eggs, suggesting uterine fluids and mixing of semen with seawater in the female's cloaca during natural mating may activate sperm motility ${ }^{16}$.

Significant variation in reproductive success was observed amongst females, with some females laying few fertile eggs within a short period of time after insemination, while others produced fertilized eggs over nearly 
four months. Females that produced fertile eggs also laid unfertilized eggs near the end of their laying period suggesting that they may not have had sufficient viable sperm stored to fertilize all ova. This pattern could be due to improper timing of insemination. For females where AI of both uteri was bilaterally successful, the number of fertilized eggs cases laid was similar to that of naturally mated, recently collected in situ females ${ }^{3}$ and naturally mated aquarium females ${ }^{4,5}$. Of the 20 females inseminated, five did not produce any fertile eggs following insemination, including two females that were inseminated with the lowest number of sperm, possibly indicative of insufficient sperm numbers. The remaining three females received similar concentrations of sperm to fertile females inseminated with semen from the same male, though using different ejaculates, which likely precludes sperm placement issues, and might highlight gamete incompatibility and individual female fertility differences.

A wide range of fertility rates sometimes was observed for the same inseminate. This suggests that latent factors associated with the female may be more important in determining the success of a trial than inseminate characteristics, which has been shown for other species ${ }^{24,41}$. Females sometimes suspended egg laying for weeks or months after insemination. Similar to the unpredictable laying habits that were observed for this study, large deviations in the number of eggs laid by females in consecutive reproductive seasons has been reported for whitespotted ${ }^{5}$ and brownbanded bamboo females ${ }^{42}$. Timing of insemination trials is another important factor that may affect success of AI procedures. Actively ovipositing females were chosen for AI trials but in situ females mate three months before their laying season ${ }^{3}$. This temporal separation of a seasonal cycle for in situ sharks may be part of the reason for the observed unpredictable oviposition after AI for sharks in managed care. Zoos and aquariums manage closed populations by recommending pairings of animals that sometime require transport of individuals between institutions so the development of assisted reproductive techniques, including AI, to manage breeding is one solution that avoids risks associated with animal transfers.

An important consideration for AI studies in species that have facultative parthenogenesis as a reproductive strategy, is confirming parentage 7 . During this study, six females or $12 \%$ of the population laid one or more parthenotes during the study, two females confirmed from AI trials and minimally 4 additional females from monitoring the general population. Importantly, three parthenotes among fertilized hatchlings were confirmed in the same clutch for two females, underscoring the ability to switch reproductive modes within a very short timeframe, 10, 80 and 83 days, and in the same reproductive season. Previously the minimum time for switching between parthenogenesis and sexual development was nearly a year and between consecutive reproductive cycles for the same eagle ray female ${ }^{34}$. To our knowledge, this is the first occurrence of both pathenogenesis and sexual reproduction occurring within the same reproductive cycle for any fish.

Parthenogenesis is observed most often among females maintained without a male in managed care, or who are assumed to have been unsuccessful in finding a mate in the wild (sawfish). However, facultative parthenogenesis may be more prevalent than realized and occur normally in a small percentage of offspring for many shark and ray species. The realization that parthenotes may occur within the same clutch as sexually produced young, raises important questions for population managers. It should be noted that in this study females were housed without a male, and it is possible that there may be environmental drivers to initiate parthenogenesis that are not impacted by AI. Similar low percentages in background rates of parthenotes of females maintained without a male lend credence to this hypothesis. Future studies should include measuring the degree of incidence of parthenotes in populations with and without a male, to generate data that will allow more accurate population modeling. Microsatellite markers are commonly used to distinguish between individuals, establish relatedness, and prove paternity or parthenogenesis for whitespotted bamboo sharks; but because of a lack of diversity in the existing markers, possibly due to repeated pairings of the same individuals within an institution that leads to inbreeding, additional loci were required to confirm parentage $e^{7,43}$.

Results demonstrate AI combined with cold storage of semen is a practical tool for gene transfer between institutions or populations. Future research should include developing protocols for cryopreservation of shark sperm to increase the flexibility for timing of AI procedures and preserve gametes for transfer between populations worldwide. This provides a mechanism for moving genes without the need to transport sharks, removing a welfare consideration of potential transport stress. Additionally, the long-term use of this technique might be to augment in situ populations, allowing gene flow into, and out of wild populations, utilizing semen collected under short-term restraint as a sustainable resource, while eliminating concerns of long-term international transport that permanently depletes the same genes.

\section{Methods}

Animals and housing. Male $(\mathrm{n}=19)$ and female $(\mathrm{n}=20)$ whitespotted bamboo sharks (Chiloscyllium plagiosum) were housed at Association of Zoos \& Aquariums (AZA) institutions: Adventure Aquarium, The Florida Aquarium, Aquarium of the Pacific and Ripley's Aquarium of the Smokies. Enclosures ranged in volume from 5,500-55,000 L with seawater temperature $22-25^{\circ} \mathrm{C}$ without seasonal temperature changes. Photoperiod was constant (13-15L:8-11D) except for select trials at Aquarium of the Pacific which had a natural photoperiod. Maturity of males was confirmed by the degree of clasper calcification, ability to rotate at the base, and splay open at the tip ${ }^{44}$. The study was carried out in compliance with the ARRIVE guidelines and was approved by the South-East Zoo Alliance for Reproduction \& Conservation (SEZARC) Institutional Animal Care and Use Committee (IACUC). All experiments were performed in accordance with institutional guidelines.

Semen collection. Semen collection was investigated by conducting and comparing two techniques- catheterization and manual expression. For semen collection by catheterization, sharks were anesthetized using $100 \mathrm{mg} / \mathrm{L}$ tricaine methanesulfonate (MS-222) (Western Chemical, Ferndale, WA, USA) buffered with $200 \mathrm{mg} / \mathrm{L}$ sodium bicarbonate. Sharks were dorsoventrally rotated, held at the water surface, and seawater drained from the cloaca. A sterile 8 Fr polyvinyl chloride catheter with two eyes and a rounded, closed tip was inserted $(2-4 \mathrm{~cm})$ 
through the urogenital papilla and slightly inclined left or right into an ampulla. Semen was extracted using gentle suction from a $1 \mathrm{ml}$ or $3 \mathrm{ml}$ syringe. For manual semen expression, bamboo sharks were restrained upright and out of the water, excess seawater drained from the cloaca and semen expressed using moderate bilateral ventral pressure on the region of the body immediately cranial to the pelvic girdle ${ }^{11}$. Semen was collected into sterile $1.5 \mathrm{ml}$ conical microcentrifuge tubes and kept at ambient $\left(\sim 24^{\circ} \mathrm{C}\right)$ temperature until processing. Semen samples were collected from individuals staggered throughout the year to encompass all months except September and December.

Semen and sperm assessment. Semen volume was measured using a calibrated pipette. Semen osmolarity was measured using a freezing point depression method (Fiske Model 210 Micro-Osmometer, Advanced Instruments Inc., MA, USA) and $\mathrm{pH}$ using $\mathrm{pH}$ strips (ColorpHast, EMD Millipore, Billerica, MA, USA). Sperm concentration was determined using a hemocytometer after diluting semen with fresh water $(1: 1000)$ to render the sperm immotile. Motility was assessed using $3 \mu \mathrm{l}$ raw or diluted semen (1:100 artificial seawater (ASW), 1050 mOsm, Sigma S9883, St Louis, Mo. USA). Total motility (\%) was defined as the number of moving sperm and progressive motility (\%) was assessed as any sperm moving with forward progression. Status was assessed on a $0-5$ scale with 0 for no movement and 5 for very rapid linear progression ${ }^{45}$. Sperm morphology was assessed using phase contrast microscopy by examining one hundred sperm per ejaculate at $100 \times$ oil immersion and reported as a percentage.

Sperm plasma membrane integrity (PMI), previously validated for use with elasmobranchs ${ }^{22}$, was assessed by incubating ASW diluted sperm suspensions in the dark for 10 min with $200 \mathrm{nM}$ SYBR-14 and $24 \mu \mathrm{M}$ propidium iodide (LIVE/DEAD Sperm Viability Kit L-7011, Molecular Probes, Inc., Eugene, Oregon, USA) and counting 100 cells using an epifluorescence microscope (Olympus B-Max 60) with filter cube U-M51005 for dual wavelength excitation. Spermatozoa fluorescing green over the head region were assessed as plasma membrane intact, and sperm fluorescing partially red or red over the head region were assessed as plasma membrane damaged ${ }^{46}$.

Acrosome presence was investigated using fluorescein isothiocyanate conjugated Arachis hypogaea agglutinin (PNA-FITC). Semen smears were made using $20 \mu \mathrm{l}$ of semen diluted 1:100 with ASW evenly spread onto an alcohol-cleaned glass slide and allowed to air-dry. After drying, the slide was flooded with $200 \mu$ PNA-FITC $(100 \mu \mathrm{g} / \mathrm{ml})$ and incubated in a dark humidified incubation chamber for $15 \mathrm{~min}$ at room temperature. The smear was rinsed to remove excess stain and a wet-mount examined using an epifluorescence microscope (Olympus B-Max 60) with filter cube U-M51005.

Confocal and scanning electron microscopy. An aliquot of raw semen was preserved 1:10 in 0.1 M Sorenson's phosphate buffer supplemented with $0.02 \% \mathrm{CaCl}_{2}, 0.35 \mathrm{M}$ sucrose, $3.2 \%$ paraformaldehyde, and $2.5 \%$ glutaraldehyde for microscopy. Preserved sperm was stained for PMI, as described above, and imaged using a laser-scanning, confocal microscope (Zeiss 710, Thornwood, NY, USA) coupled with a Zeiss Axiophot inverted microscope in line scanning mode with a C-Apochromat $40 \times$ Korr M27 (NA 1.2) water immersion objective, and ZEN software (Zeiss, Jena, Germany). Imaging was performed using differential interference contrast and fluorescence to highlight the boundary between the head and midpiece. Fluorescence was accomplished with laser excitation at $488 \mathrm{~nm}$ and $561 \mathrm{~nm}$ and emission collected between 500-550 $\mathrm{nm}$ and 575-610 nm. The length of the acrosome, head, midpiece and flagellum for 10 sperm per shark from five sharks were measured from digital photomicrographs using Fiji ${ }^{47}$. For scanning electron microscopy, preserved semen was dehydrated in increasing concentrations of ethanol and critical point dried (Tousimis Autosamdri-815B, Rockville, MD). Samples were mounted onto aluminum stubs, sputter coated with Au-Pd (Leica EM ACE600, Wetzlar, Germany) and examined using a Hitachi S-4700 scanning electron microscope (SEM).

Short-term semen storage. Cold storage of whitespotted bamboo shark sperm was investigated using fresh ejaculates from four sharks with total motility of $\geq 75 \%$. Two medias were investigated: artificial seawater (ASW), a simple osmotically balanced salt solution and Hank's balanced salt solution (E-HBSS; $5 \mathrm{mM} \mathrm{CaCl}_{2}$, $3 \mathrm{mM} \mathrm{MgCl}_{2}, 6 \mathrm{mM} \mathrm{KCl}, 0.281 \mathrm{M} \mathrm{NaCl}, 1 \mathrm{mM} \mathrm{NaH}_{2} \mathrm{PO}_{4}, 8 \mathrm{mM} \mathrm{NaHCO}_{3}, 6 \mathrm{mM}$ glucose, $0.1 \mathrm{mM}$ trimethylamine N-oxide (TMAO), $0.35 \mathrm{M}$ urea, $0.5 \mathrm{mM} \mathrm{Na}_{2} \mathrm{SO}_{4}, \mathrm{pH}$ 7), an osmotically balanced salt solution with an energy substrate (glucose), to determine if a supplemented medium would be more supportive of cold-stored sperm longevity. Ejaculates were divided into three aliquots and stored raw or extended 1:5 in ASW or after washing to remove seminal plasma (diluted $1: 10$, centrifuged at $800 \times g$ for 3 min and the sperm pellet resuspended 1:5 in ASW or E-HBSS). Aliquots were stored at $4{ }^{\circ} \mathrm{C}$ and evaluated as described previously for total motility and PMI on days 1, 2, 3, 5, 7, 12 and 18 .

Artificial insemination. Whitespotted bamboo sharks $(n=20)$ housed without a male for 2 years were selected for artificial insemination (AI). Females were housed individually in 500-1500 L habitats to monitor egg laying and embryo development six weeks before insemination. In preparation for AI, females were anesthetized using Propofol $2.5 \mathrm{mg} / \mathrm{kg}$ intraveneously or MS-222 50-75 mg/L immersion. Once anesthetized, the female was held in dorsal recumbency with her head and gills submerged and semen transferred using a sterile, semi-rigid $14 \mathrm{~cm} 3.5 \mathrm{Fr}$ polypropylene catheter inserted $8-10 \mathrm{~cm}$ through the cloaca and diverted laterally into an oviduct, delivering half of the inseminate to each side of the paired reproductive tract. If an egg case was present in the oviduct, semen was placed cranial to the egg case by gently manipulating the catheter around the egg case or manually extracting the egg case before insemination.

Habitats were checked daily for egg cases and hatchlings. Egg cases were tagged with the date of oviposition. Egg cases that did not contain a yolk (referred to as 'wind cases' ${ }^{48}$ ) were discarded and not included in analyses. Eggs were candled to confirm fertility by observation of a moving embryo. Egg cases collected before AI also 
were monitored for potential embryo development but were not included in data analyses. Oviposition was monitored for 70-216 days after insemination.

Females were inseminated with freshly collected or cold-stored semen that was raw or diluted 1:1 with seawater, at concentrations of 3-750 $\times 10^{6}$ total sperm (Supplemental Table 1). Cold-stored semen transferred between institutions was shipped overnight at $4{ }^{\circ} \mathrm{C}$ in a stryofoam box, containing a cold pack insulated from direct contact with the semen sample. For AI procedures, samples were equilibrated to room temperature prior to insemination. Motility for all inseminates was $\geq 90 \%$ with the exception of one 24 -h and one 48 -h cold-stored sample (Supplemental Table 1). Fertility was calculated as the percentage of eggs that developed an embryo, and hatchability as the percentage of eggs that hatched out of the total number of egg cases laid. Hatchability and fertility were adjusted to reflect hatchlings derived only from AI by excluding confirmed parthenotes (see below). Fertility duration was calculated as the number of days each female laid fertile eggs.

Parthenogenesis. To determine the general incidence of parthenogenesis in whitespotted bamboo sharks, all eggs laid during 105 consecutive days were collected from a habitat housing 48 mature females but no males. Eggs were incubated and monitored for development as described previously. The frequency of parthenogenesis was calculated as the ratio of the number of confirmed parthenotes (described below) to the total number of eggs (excluding wind cases) and the total number of fertile eggs. Microsatellite data from the embryos and hatchlings was used to estimate the minimum number of parthenote-laying females by reconstructing maternal genotypes. For one sample (P8) the offspring was consistent with a parthenote and it was included in analyses as a parthenote, however, missing loci prevented confirmation.

Paternity. Whole blood or a fin clip from the trailing edge of the first or second dorsal fin was collected from dams, sires, embryos and hatchlings and stored in DMSO buffer (20\% DMSO, 250 mM EDTA, saturated $\mathrm{NaCl}, \mathrm{pH}$ 7.5). Paternity following AI was confirmed using techniques and four microsatellite loci previously developed for this species ${ }^{7,43}$, together with five new species-specific microsatellite loci developed for this study (Cp1930, Cpl962, Cpl1141, Cpl1161, and Cpl1163) following existing methodology ${ }^{49}$. Sequences for new loci have been deposited into Genbank (Accession numbers MT237441-MT237445). Polymerase chain reaction (PCR) conditions for previously developed loci follow Ding et al. (2009) and Feldheim et al. (2010). PCRs for new loci were performed in $10 \mu \mathrm{l}$ volumes with $1 \times \mathrm{PCR}$ buffer $(10 \mathrm{mM}$ Tris- $\mathrm{HCl}, 50 \mathrm{mM} \mathrm{KCl}, \mathrm{pH} 8.3), 10 \times \mathrm{BSA}$, $1.0 \mathrm{MgCl}_{2}$ (Cpl1161), $1.5 \mathrm{mM} \mathrm{MgCl}_{2}$ (Cpl930 and Cpl1141), or $2.5 \mathrm{mM} \mathrm{MgCl}_{2}$ (Cpl962 and Cpl1163), $0.12 \mathrm{mM}$ of each dNTP, $0.04 \mu \mathrm{M}$ forward primer tagged with an M13 sequence on the $5^{\prime}$ end ${ }^{50}, 0.16 \mu \mathrm{M}$ of both the reverse primer and a fluorescently labeled universal M13 primer, and $1 \mathrm{U}$ Taq polymerase. Thermal cycling began with an initial denaturation step of $94^{\circ} \mathrm{C}$ for four minutes was followed by 30 cycles of $94{ }^{\circ} \mathrm{C}$ for $15 \mathrm{~s}$, $58^{\circ} \mathrm{C}$ for $15 \mathrm{~s}$, and $72{ }^{\circ} \mathrm{C}$ for $45 \mathrm{~s}$, followed by eight cycles of $94{ }^{\circ} \mathrm{C}$ for $15 \mathrm{~s}, 53{ }^{\circ} \mathrm{C}$ for $15 \mathrm{~s}$, and $72{ }^{\circ} \mathrm{C}$ for $45 \mathrm{~s}$. A final elongation step of $72{ }^{\circ} \mathrm{C}$ for 10 min concluded each PCR. For locus Cpl1161, a touchdown PCR was performed as follows: an initial denaturation step of $94^{\circ} \mathrm{C}$ for four minutes followed by 16 cycles of $94{ }^{\circ} \mathrm{C}$ for $15 \mathrm{~s}$, $68^{\circ} \mathrm{C}$ for $15 \mathrm{~s}$ (decreasing $0.5^{\circ} \mathrm{C}$ every cycle), and $72{ }^{\circ} \mathrm{C}$ for $45 \mathrm{~s}$, followed by 20 cycles of $94{ }^{\circ} \mathrm{C}$ for $15 \mathrm{~s}, 60^{\circ} \mathrm{C}$ for $15 \mathrm{~s}$, and $72{ }^{\circ} \mathrm{C}$ for $45 \mathrm{~s}$, and a final elongation of $72{ }^{\circ} \mathrm{C}$ for $10 \mathrm{~min}$. PCR products $(0.5 \mu \mathrm{l}$ each $)$ and $1.0 \mu \mathrm{l}$ of an internal ladder (ALEXA-725) ${ }^{51}$ were combined with $8.5 \mu$ l HiDi Formamide and run on an ABI 3730 DNA Analyzer (Thermo Fisher Scientific). Genotypes were scored using Geneious v. v.10.0.3 (http://www.geneious. $\mathrm{com})^{52}$. Paternity was determined by matching microsatellite alleles between the putative sire and dam to 88 of 112 developing embryos or hatchlings. Homozygosity for maternal alleles at all microsatellite loci coupled with a lack of paternal alleles was used to identify parthenotes ${ }^{7}$.

Descriptive statistics were calculated for semen and sperm parameters. Changes in PMI and motility during cold storage were examined with linear mixed effects models fit by restricted maximum likelihood with day, storage method (raw, E-HBSS or ASW) and their interaction modeled sequentially as fixed factors and repeated measures collected from the same fish accounted for by including shark as a random factor in models. Model selection was based on significance of a likelihood ratio tests between models fit by maximum likelihood that differed in fixed effects only. Model parsimony was maximized using Bayesian Information Criterion. Model residuals were examined using plots for normality, non-linearity, homoscedasticity and outliers. Pearson correlation was used to determine the relationship between motility and PMI for cold-stored semen samples. Differences in fertility for AI trials between ejaculates split and inseminated raw and diluted were evaluated using a paired t-test. Statistical analyses were conducted using R Version 4.0.0 $0^{53}$ with ggplot2 Version 3.3.0 ${ }^{54}, \operatorname{lme} 4$ Version 1.1-23 and a critical probability level of 0.05 .

\section{Data availability}

The datasets generated during and/or analysed during the current study are included in this published article (and its Supplementary Information files) or available from the corresponding author on reasonable request. Sequences for new whitespotted bamboo microsatellite loci have been deposited into Genbank, Accession numbers MT237441-MT237445.

Received: 18 November 2020; Accepted: 19 February 2021

Published online: 13 May 2021

\section{References}

1. Kyne, P.M. \& Burgess, G. H. Chiloscyllium plagiosum. The IUCN Red List of Threatened Species 2006. e.T60222A12325334. (2006). Available at: https://doi.org/10.2305/IUCN.UK.2006.RLTS.T60222A12325334.en. (Accessed: 31st August 2018) 
2. Dudgeon, C.L., Bennett, M.B. \& Kyne, P. M. Chiloscyllium punctatum. The IUCN Red List of Threatened Species 2016: e.T41872A68616745. (2016). Available at: https://doi.org/10.2305/IUCN.UK.2016-1.RLTS.T41872A68616745.en. (Accessed: 31st August 2018)

3. Chen, W. K. \& Liu, K. M. Reproductive biology of whitespotted bamboo shark Chiloscyllium plagiosum in northern waters off Taiwan. Fish. Sci. 72, 1215-1224 (2006).

4. Masuda, M. Mating, spawning and hatching of the white spotted bamboo shark in an aquarium. Jpn. J. Ichthyol. 45, 29-35 (1998).

5. Miki, T. Spawning, hatching, and growth of the whitespotted bamboo shark, Chiliscyllium plagiosum. J. Jpn. Assoc. Zool. Aqua. 36, 10-19 (1994).

6. Nau, M. R., O’Brien, J. K., Schmitt, T. L., Nollens, H. H. \& Robeck, T. R. Diagnostic assessment of reproductive status in whitespotted bamboo sharks (Chiloscyllium plagiosum). Anim. Reprod. Sci. 197, 48-57 (2018).

7. Feldheim, K. A. et al. Shark virgin birth produces multiple, viable offspring. J. Hered. 101, 374-377 (2010).

8. Straube, N., Lampert, K. P., Geiger, M. F., Weiß, J. D. \& Kirchhauser, J. X. First record of second-generation facultative parthenogenesis in a vertebrate species, the whitespotted bambooshark Chiloscyllium plagiosum. J. Fish Biol. 88, 668-675 (2016).

9. Daly, J. J. \& Jones, R. The use of reproductive technologies in breeding programs for elasmobranchs in aquaria. in The Elasmobranch Husbandry Manual II: Recent Advances in the Care of Sharks, Rays and their Relatives. (eds. Smith, M. et al.) 363-374 (Special Publication of the Ohio Biological Survey, 2017).

10. Penfold, L. M. \& Wyffels, J. T. Reproductive Science in Sharks and Rays. In Advances in experimental medicine and biology Vol. 1200 (eds Comizzoli, P. et al.) 465-488 (Springer, Cham, 2019).

11. Masuda, M., Izawa, Y., Kametuta, S., Ikuta, H. \& Isogai, T. Artificial insemination of the cloudy catshark. J. Jpn. Assoc. Zool. Gard. Aquariums 44, 39-43 (2003).

12. Masuda, M. et al. Artificial insemination of the white-spotted bamboo shark, Chiloscyllium plagiosum. J. Jpn. Assoc. Zool. Gard. Aquariums 46, 91-96 (2005).

13. Luer, C. A., Walsh, C. J., Bodine, A. B. \& Wyffels, J. T. Normal embryonic development in the clearnose skate, Raja eglanteria, with experimental observations on artificial insemination. Environ. Biol. Fishes 80, 239-255 (2007).

14. Keschumras, N., Daochai, C. \& Chansue, N. Evaluation of fresh and chilled semen from ocellate river stingray (Potamotrygon motoro). Proc. 14th Chulalongkorn Univ. Vet. Conf. CUVC 2015 Responsible Lives April 20-2, 255-256 (2015).

15. Daly, J., Holland, M. K. \& Galloway, D. B. Preliminary investigations on sperm cryopreservation of a stingray, the sparsely spotted stingaree. In Cryopreservation in Aquatic Species 2nd Edition. (eds. Tiersch, T. R. \& Green, C. C.) 337-344 (World Aquaculture Society, 2011).

16. Minamikawa, S. \& Morisawa, M. Acquisition, initiation and maintenance of sperm motility in the shark, Triakis scyllia. Comp. Biochem. Physiol. Part A Physiol. 113, 387-392 (1996).

17. Morales-Gamba, R. D., Caldas, J. S., Godoy, L. \& Marcon, J. L. Sperm characterization of the Amazonian freshwater cururu stingray Potamotrygon wallacei (Potamotryogonidae): basic knowledge for reproduction and conservation plans. Zygote 27, 259-261 (2019).

18. Dzyuba, V. et al. Sperm motility in ocellate river stingrays: evidence for post-testicular sperm maturation and capacitation in Chondrichthyes. J. Zool. 307, 9-16 (2019).

19. Dzyuba, V. et al. Sperm motility and lipid composition in internally fertilizing ocellate river stingray Potamotrygon motoro. Theriogenology 130, 26-35 (2019).

20. Dzyuba, V., Ninhaus-Silveira, A., Veríssimo-Silveira, R., Rodina, M. \& Dzyuba, B. Sperm antioxidant system in ocellate river stingray Potamotrygon motoro at transition from seminal vesicle to cloaca. Fish Physiol. Biochem. 46, 1975-1980 (2020).

21. Pratt, H. L. \& Tanaka, S. Sperm storage in male elasmobranchs: a description and survey. J. Morphol. 219, 297-308 (1994).

22. Wyffels, J. T. et al. Testosterone and semen seasonality for the sand tiger shark Carcharias taurus. Biol. Reprod. 102, 876-887 (2020).

23. Christensen, J. M. \& Tiersch, T. R. Refrigerated storage of channel catfish sperm. J. World Aquac. Soc. 27, 340-346 (1996).

24. Babiak, I. \& Dabrowski, K. Refrigeration of rainbow trout gametes and embryos. J. Exp. Zool. Part A Comp. Exp. Biol. 300, 140-151 (2003).

25. Yasui, G. S. et al. Improvement of gamete quality and its short-term storage: an approach for biotechnology in laboratory fish. Animal 39, 464-470 (2014)

26. Ubilla, A., Fornari, D., Figueroa, E., Effer, B. \& Valdebenito, I. Short-term cold storage of the semen of rainbow trout Oncorhynchus mykiss (Walbaum, 1792) incorporating DMSO in the sperm diluent. Effects on motility and fertilizing capacity. Aquac. Res. 46, 37-44 (2015).

27. Sun, C., Huang, C., Su, X., Zhao, X. \& Dong, Q. Optimization of handling and refrigerated storage of guppy Poecilia reticulata sperm. J. Fish Biol. 77, 54-66 (2010).

28. Contreras, P. et al. Effects of short-term storage on sperm function in fish semen: a review. Rev. Aquac. 12, 1373-1389 (2020).

29. Feldheim, K. A. et al. Multiple births by a captive swellshark Cephaloscyllium ventriosum via facultative parthenogenesis. J. Fish Biol. 90, 1047-1053 (2017).

30. Chapman, D. D. et al. Virgin birth in a hammerhead shark. Biol. Lett. 3, 425-427 (2007).

31. Chapman, D. D., Firchau, B. \& Shivji, M. S. Parthenogenesis in a large-bodied requiem shark, the blacktip Carcharhinus limbatus. J. Fish Biol. 73, 1473-1477 (2008).

32. Robinson, D. P., Baverstock, W., Al-Jaru, A., Hyland, K. \& Khazanehdari, K. A. Annually recurring parthenogenesis in a zebra shark Stegostoma fasciatum. J. Fish Biol. 79, 1376-1382 (2011).

33. Dudgeon, C. L., Coulton, L., Bone, R., Ovenden, J. R. \& Thomas, S. Switch from sexual to parthenogenetic reproduction in a zebra shark. Sci. Rep. 7, 40537 (2017).

34. Harmon, T. S., Kamerman, T. Y., Corwin, A. L. \& Sellas, A. B. Consecutive parthenogenetic births in a spotted eagle ray Aetobatus narinari. J. Fish Biol. 88, 741-745 (2016).

35. Fields, A. T., Feldheim, K. A., Poulakis, G. R. \& Chapman, D. D. Facultative parthenogenesis in a critically endangered wild vertebrate. Curr. Biol. 25, R446-R447 (2015).

36. Hoffmann, B. \& Landeck, A. Testicular endocrine function, seasonality and semen quality of the stallion. Anim. Reprod. Sci. 57, 89-98 (1999).

37. Tanaka, S., Kurokawa, H. \& Masako, H. Comparative morphology of the sperm in chondrichthyan fishes. Mémoires du Muséum Natl. d'Histoire Nat. 166, 321-332 (1995).

38. Schiffer, C. et al. Rotational motion and rheotaxis of human sperm do not require functional CatSper channels and transmembrane Ca $2+$ signaling. EMBO J. 39, e102363 (2020).

39. Segovia, M., Jenkins, J. A., Paniagua-Chavez, C. \& Tiersch, T. R. Flow cytometric evaluation of antibiotic effects on viability and mitochondrial function of refrigerated spermatozoa of Nile tilapia. Theriogenology 53, 1489-1499 (2000).

40. Nynca, J., Dietrich, G. J., Dobosz, S., Kuźmiński, H. \& Ciereszko, A. Sperm motility rate at pH 6.5 as a useful parameter for the evaluation of rainbow trout sperm quality and usefulness for short-time storage. J. Appl. Ichthyol. 28, 930-933 (2012).

41. Holt, W. V. Fundamental aspects of sperm cryobiology: the importance of species and individual differences. Theriogenology 53 , 47-58 (2000).

42. Harahush, B. K., Fischer, A. B. P. \& Collin, S. P. Captive breeding and embryonic development of Chiloscyllium punctatum Muller \& Henle, 1838 (Elasmobranchii: Hemiscyllidae). J. Fish Biol. 71, 1007-1022 (2007).

43. Ding, S.-X.X., Pan, Y., Zeng, H.-S.S. \& Wang, J. Characterization of 12 polymorphic microsatellite loci for the whitespotted bamboo shark (Chiloscyllium plagiosum Bennett). Mol. Ecol. Resour. 9, 1398-1400 (2009). 
44. Clarke, E. \& von Schmidt, K. Sharks of the central gulf coast of Florida. Bull. Mar. Sci 15, 15-83 (1965).

45. Howard, J., Bush, R. M. \& Wildt, D. E. Semen collection, analysis and cryopreservation in nondomestic mammals. In Current Therapy in Theriogenology II (ed. Morrow, D.) 1047-1053 (Philadelphia, 1986).

46. Garner, D. L., Johnson, L. A., Yue, S. T., Roth, B. L. \& Haugland, R. P. Dual DNA staining assessment of bovine sperm viability using SYBR-14 and propidium iodide. J. Androl. 15, 620-629 (1994).

47. Schindelin, J. et al. Fiji: an open-source platform for biological-image analysis. Nat. Methods 9, 676-682 (2012).

48. Wyffels, J. T. Embryonic development of Chondrichthyan fishes-a review. In Development of Non-Teleost Fishes (eds Kunz, Y. W. et al.) 1-103 (Science Publishers, Enfield, 2009).

49. Glenn, T. C. \& Schable, N. A. Isolating microsatellite DNA loci. Methods Enzymol. 395, 202-222 (2005).

50. Schuelke, M. An economic method for the fluorescent labeling of PCR fragments. Nat. Biotechnol. 18, 233-234 (2000).

51. Maddox, J. D. \& Feldheim, K. A. A cost-effective size standard for fragment analysis that maximizes throughput on five dye set platforms. Conserv. Genet. Resour. 6, 5-7 (2014).

52. Kearse, M. et al. Geneious Basic: an integrated and extendable desktop software platform for the organization and analysis of sequence data. Bioinformatics 28, 1647-1649 (2012).

53. R Core Team. R: A language and environment for statistical computing. R Foundation for Statistical Computing, Vienna, Austria. (2016).

54. Wickham, H. ggplot2: Elegant Graphics for Data Analysis. (Springer-Verlag, 2009).

\section{Acknowledgments}

The authors are grateful to The SeaWorld \& Busch Gardens Conservation Fund that provided grant funding to JTW and LMP. A project of this undertaking requires the collaboration, cooperation and expertise of many people to accomplish. We thank the entire husbandry and veterinary staff at Ripley's Aquariums, The Florida Aquarium, Adventure Aquarium and Aquarium of the Pacific. Confocal and SEM access at University of Delaware for JTW was supported by grants from the NIH-NIGMS (P20 GM103446), the NSF (IIA-1301765) and the State of Delaware and equipment was acquired with the Delaware INBRE Grant P20 GM103446.

\section{Author contributions}

J.W. conceived the project, conducted semen collection and artificial insemination procedures, collated institutional data, completed statistical analysis and drafted the manuscript. L.A. and F.B. conducted semen collection and artificial insemination procedures and collected egg data. M.H. and A.F. collected semen samples for assessment and shipped cold stored semen for insemination procedures between institutions. K.F. developed new microsatellite markers for whitespotted bamboo sharks and genotyped potential parents and offspring. L.P. provided project oversight and manuscript revisions. All authors reviewed the manuscript.

\section{Competing interests}

The authors declare no competing interests.

\section{Additional information}

Supplementary Information The online version contains supplementary material available at https://doi.org/ 10.1038/s41598-021-88568-y.

Correspondence and requests for materials should be addressed to J.T.W.

Reprints and permissions information is available at www.nature.com/reprints.

Publisher's note Springer Nature remains neutral with regard to jurisdictional claims in published maps and institutional affiliations.

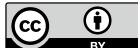

Open Access This article is licensed under a Creative Commons Attribution 4.0 International License, which permits use, sharing, adaptation, distribution and reproduction in any medium or format, as long as you give appropriate credit to the original author(s) and the source, provide a link to the Creative Commons licence, and indicate if changes were made. The images or other third party material in this article are included in the article's Creative Commons licence, unless indicated otherwise in a credit line to the material. If material is not included in the article's Creative Commons licence and your intended use is not permitted by statutory regulation or exceeds the permitted use, you will need to obtain permission directly from the copyright holder. To view a copy of this licence, visit http://creativecommons.org/licenses/by/4.0/.

(C) The Author(s) 2021 